\title{
Development and evaluation of a multi-heat source deep fat fryer
}

\author{
Ogunmoyela, O.A.B., Jimoh*, M.O., and Ogabi, O.N. \\ Department of Food Science and Technology, Bells University of Technology, Ota, Nigeria \\ ${ }^{*}$ Corresponding author E-mail: omotayojimoh50@yahoo.com
}

\begin{abstract}
Deep fat frying constitutes a reasonable percentage in cottage food preparation across the globe. The need to upgrade the local deep fat frying process to be more user friendly, efficient and versatile is the basis of the development of an appropriate portable, low-cost and affordable multi-heat source deep fryer. The machine was evaluated using wheat flour dough to produce chin-chin, a local fried wheat product. Performance of groundnut, corn and soya oils under different heat sources; gas, electricity and charcoal energy were considered. The average capacity of the machine was found to be $7.69 \mathrm{~kg} / \mathrm{h}$ when using electric energy, $8.52 \mathrm{~kg} / \mathrm{h}$ when using gas energy and $6.00 \mathrm{~kg} / \mathrm{h}$ when using charcoal energy. Heat requirement of the machine was $1428 \mathrm{~W}$. The fat uptake of the chin-chin fried with groundnut oil was $0.51,0.49$ and $0.67 \mathrm{~g}$ for gas, electric and charcoal energy respectively; for soya oil $0.47,0.43$ and $0.63 \mathrm{~g}$ respectively; and for corn oil $0.46,0.41$ and $0.57 \mathrm{~g}$ respectively. Vitamin A retention in soya, groundnut and corn oil was 13515,18485 and 34242 IU/kg respectively when using gas energy; 14727, 22243 and 38182 IU/kg respectively when using charcoal energy; 20606, 27273 and 41030 IU/kg respectively when using electric energy. Thus, corn oil gave the least fat uptake when using electric energy; it also gave the highest vitamin A retention, given the mandatory vitamin A level of $30000 \mathrm{IU} / \mathrm{kg}$ in flour and $20000 \mathrm{IU} / \mathrm{kg}$ in vegetable oils under the National Food Fortification Programme in Nigeria.
\end{abstract}

Keywords: design, frying, experiment, fat uptake, vitamin A, chin-chin

\section{INTRODUCTION}

The Latin and Greek words for 'frying' originate from word 'roasting', suggesting that frying may have developed from roasting (Dogan et al., 2005). The simplest deep-fat frying process is conducted in a kettle of oil heated on a stove or over an open fire in which small batches of food are immersed in hot oil and removed when fried as determined by the experience of the cook. The first real technological advance in frying was the introduction of continuous cooking which involves the immersion of food in hot oil or fat for a given period of time, draining, cooling, and further processing or consumption (Garayo and Moreira, 2002). As the food fries, the internal cells become dehydrated and the evaporated water is partially replaced by frying oil. Frying is extremely popular kitchen 
appliances and is used in about $85 \%$ of food service establishments. It is designed to cook chicken, fish, breaded vegetables, specialized pastries, French-fried potatoes and other foods.

The cooking medium during frying is hot oil, also known as shortening, frying compound or fat. The quality of the final food product largely depends on the quality of the oil. Pintus et al., (1995) indicated that as the product fries, the inner moisture is converted to steam, creating a pressure gradient. The surface dries out causing the oil to adhere to the product surface and enter the surface of the damaged area. A wide spectrum of factors has been reported to affect oil absorption in fried food. This includes oil quality and composition, frying temperature and time, product composition, moisture content, shape, porosity, pre-frying treatment, surface treatment, initial interface tension, and crust size (Ballard and Mallikarjunan, 2006).

Frying fat influences many qualities of the finished product such as flavour, texture, shelf life and nutritional attributes. The oils that are exposed to a high temperature when left in open air are subject to thermolytic and oxidative reactions (Teye et al., 2006). These result in their partial conversion to volatile chainscission products, non-volatile oxidative derivatives and dimeric, polymeric or cyclic substances. The quality of fried foods must depend not only on the type of food and frying condition, but also on the oil used for frying. Thus, the selection of stable frying oils of good quality is of great importance to maintain a low deterioration during frying and consequently a high quality of fried foods (Mellema, 2003). When the oil is heated, it enables heat transfer due to conduction and convection, the latter being caused by free water boiling at the surface upon immersion of the moist food in hot oil. The moisture vaporizes out, and creates a path known as capillary pore, through which hot oil enters the food. The reaction occurs by the influence of oil uptake, crust formation, shrinkage and swelling, thus inducing macro- and microstructural changes (Garayo and Moreira, 2002). This influences the vapour and liquid diffusion, safety assurance, and yield final products with the taste and textural characteristics expected by the consumer. Thus, most foods with capillary porous matrices are found hygroscopic (Yamsaengsung and Moreira, 2002).

Deep-fat frying is typically conducted in a temperature range of 120 to $180^{\circ} \mathrm{C}$ (Shyu et al., 2005). Deep-fat frying is a complex process that involves simultaneous heat and mass transfer. The process induces a variety of physicochemical changes in both the food and the frying medium. The principles underlying the mechanisms of water evaporation and oil absorption are intimately related (Hussain et al., 2002). Investigation reveals that several prototype deep fat fryers have been developed. These include: open fryers which may either be single heat source or double heat sources; as well as pressure fryers designed to keep vapour inside the fryer while cooling. The frying vessel captures steam from cooked food, increasing the pressure inside the unit until no more moisture is released from the food. The pressure ranges from 34473.80-82737.12 N/m² (Innawong et al., 2006). This research is therefore aimed at designing and evaluating the performance of a multi-heat source deep fat fryer using charcoal, gas and the electricity as sources of energy in different frying oils, namely groundnut, soya and corn oil. Heat transfer mechanism and the effect of this on nutritional value of the product were also investigated.

\section{MATERIALS AND METHODS}

\section{Description of the multi-heat source deep fat fryer}

The multi-heat source deep fat fryer was designed to have multiple energy sources; charcoal, gas and the electricity. The components include the stainless steel basket, the stainless steel pot, and the exterior components such as fan switch, thermostat, electric hot plate, fan, gas burner, gas control, gas pipe, hinges, basket lifter, and charcoal compartment. The design, fabrication and performance evaluation of the machine was done with necessary modification in the Department of Food Science and Technology, Bells University of Technology, Ota, Nigeria in collaboration with an Industrial Engineering outfit, Addis Engineering Ltd at Abimbola Street along Isolo road, Lagos. The frame was divided into three rectangular but equal sections. This facilitates a standing support to the pot that was constructed and the hinges fabricated to the frame in connection with the frying pot for easy swing movement. The fry-pot was constructed to be rectangular, made of a stainless steel and constructed to sit on the frame. It was also constructed to be easily removable for easy accessibility to cleaning. The fry basket was also constructed to be rectangular, made of stainless steel and constructed to be smaller than the fry-pot for free movement when hinged. This also allows for free movement of heat by convection. The gas burner was welded to the frame constructed to support the electric radiation plate; the electric plate has a power of 1500 watt with a sensor wired into it to detect changes in temperature. Thus, when the heat gets to the set temperature, it cuts off automatically and then when below the set temperature, the temperature rises again and vice versa. The charcoal compartment was constructed on the basis of $2 \mathrm{~kg}$ of charcoal required for heating the fryer.

\section{Machine drawings}

These include major components of the machine such as stainless steel frying pot and stainless steel frying basket as shown in Figure 1, plain view of the machine as shown in Figure 2, front view of the machine as shown in 
A

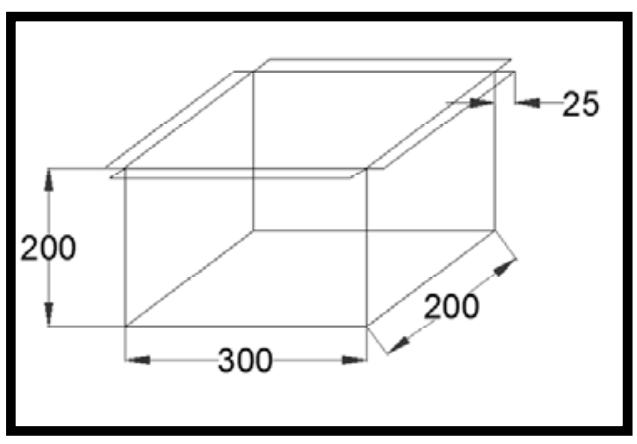

B

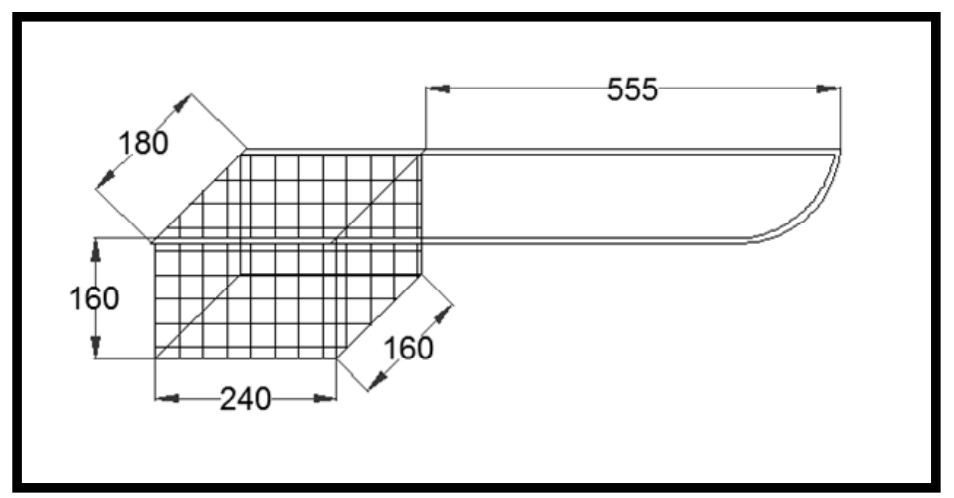

A- Stainless steel frying pot, and B- Stainless steel frying basket Figure 1. Major components of the machine.

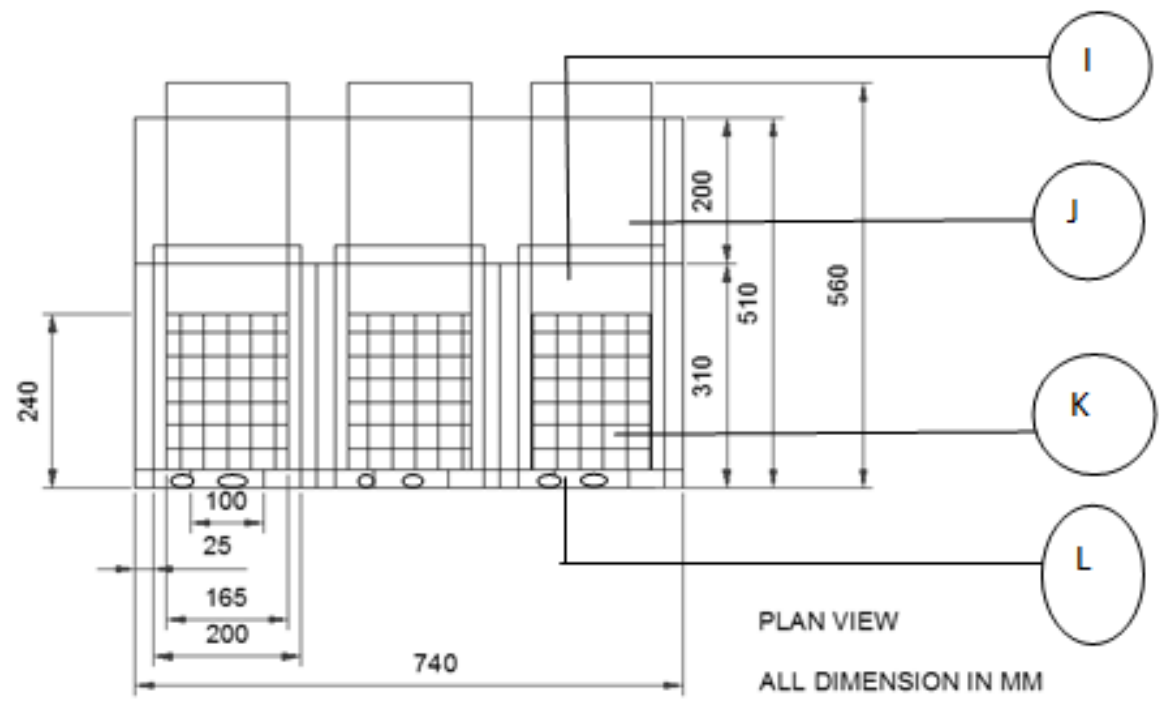

I- Stainless steel pot, J- Basket lifter, K- Stainless steel basket, and L- Hinges Figure 2. Plain view of the machine.

Figure 3 and pictorial representation of the multi-heat source deep fat fryer (MSDFF) as shown in Figure 4.

\section{Design considerations}

The machine was developed with the following considerations:

i. locally available materials at low cost was used in the fabrication of the machine. Overall cost of the machine is N50,000 only.

ii. stainless steel was used for all contact surfaces to enable easy cleaning and to prevent corrosion and contamination.

iii. the machine allows easy assembling, dismantling, adjustiments and operation. iv. the power requirement was designed to be minimal and efficient for processing of any type of food material using good quality oil. The power requirement is $1.43 \mathrm{Kw}$. vi. The machine was designed to handle various deep fat fried products such as chin-chin, plantain chips, bean flour, yam chips and wheat flour balls.

vii. the positioning of machine component parts is to enhance safety of the operator.

\section{Design calculations}

Selected materials in the development of the machine include:

i. Frying basket: stainless steel mesh (1.5 $\mathrm{mm}$ thickness) (240 mm x $160 \times 160 \mathrm{~mm}$ ) 


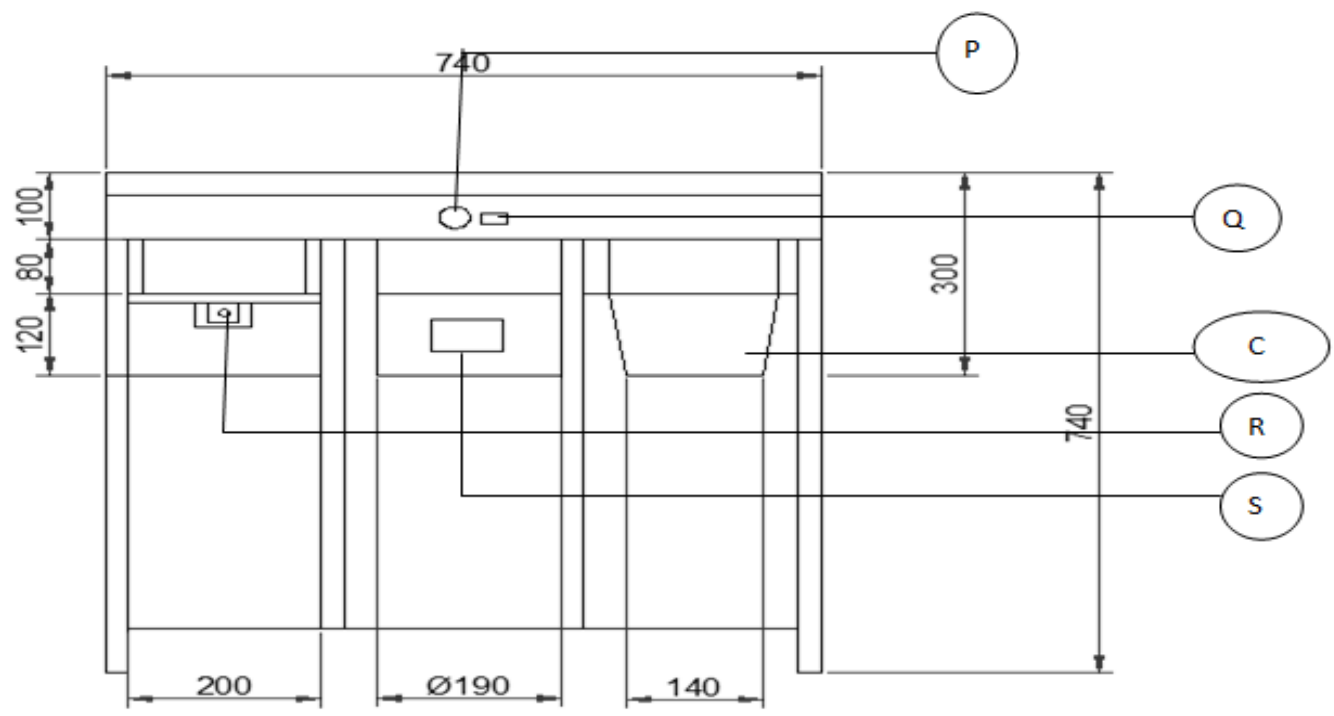

FRONT MEW

P- Thermostat, Q- Fan switch, C- Chacoal compartment, R- Gas control, and S- Electric hot plate Figure 3. Front view of the machine.

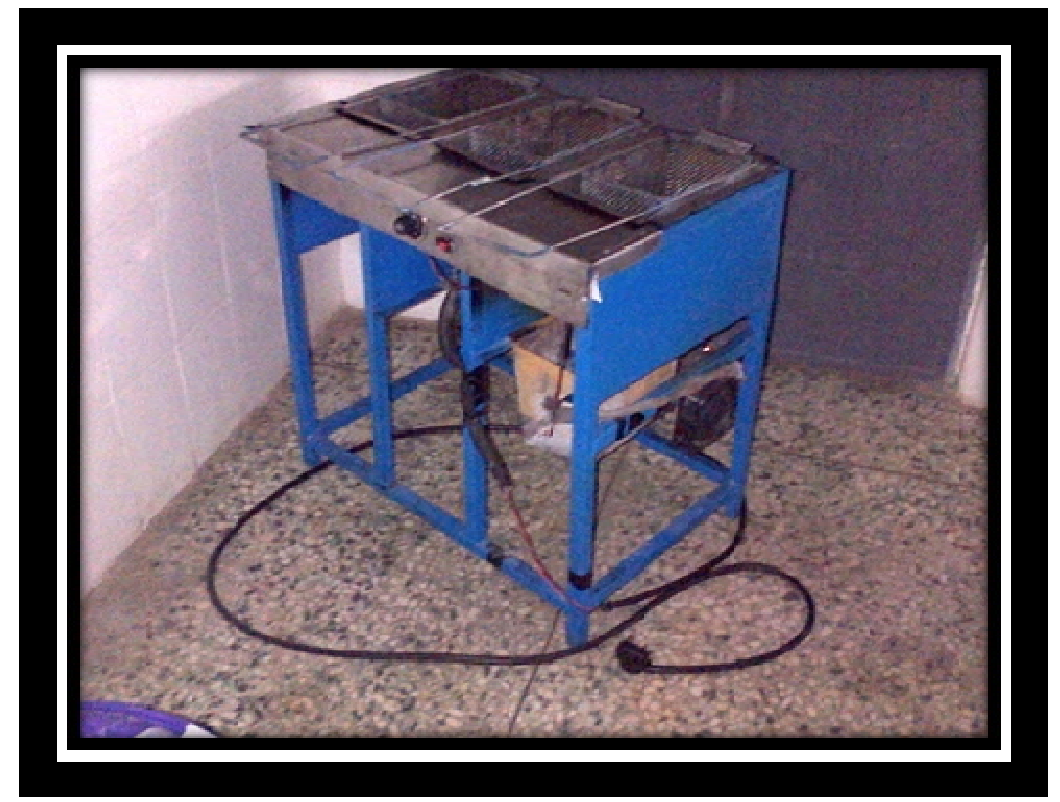

Figure 4. pictorial representation of the multi-heat source deep fat fryer (MSDFF).

ii. Frying pot: stainless steel material $(2 \mathrm{~mm}$ thickness $)$ (300 $\mathrm{mm} \times 200 \mathrm{~mm} \times 200 \mathrm{~mm}$ )

iii. Frame: $745 \mathrm{~mm} \times 500 \mathrm{~mm} \times 710 \mathrm{~mm}$,

Frame sections for three compartments: $500 \mathrm{~mm} x$ $260 \mathrm{~mm}$ each

Bended hinges: $100 \mathrm{~mm} \times 35 \mathrm{~mm} \times 10 \mathrm{~mm}$

Hot plate: 1500 watts

Gas burner: $\phi 75 \mathrm{~mm}$ by $150 \mathrm{~mm}$ by $50 \mathrm{~mm}$

Fan: $75 \mathrm{~mm}$ by $75 \mathrm{~mm}$ iv. Determination of Heat Transfer rate: When a temperature gradient exists in a body during frying, experience has shown that there is an energy transfer from the high-temperature region to a low-temperature region. The energy transferred across the frying pot is by conduction and that the heat-transfer rate per unit area is proportional to the normal temperature gradient (Jimoh, 2014): 


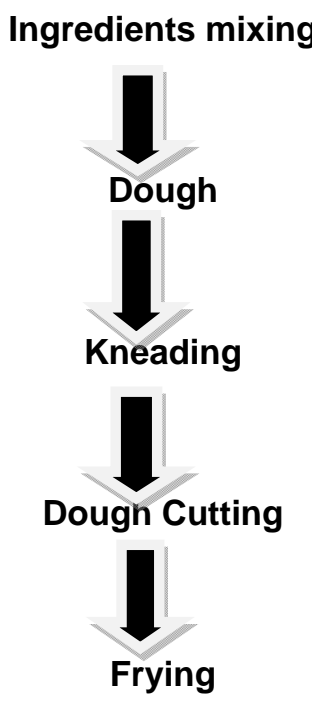

Figure 5- Flow chart for the production of chin-chin.

Source: (Greg and others 2008)

$$
\frac{q}{A}=\frac{\partial T}{\partial x}
$$

When proportionality constant is introduced,

$$
q=-K A \frac{\partial T}{\partial x}
$$

Where $q$ is heat transferred by conduction, $K$ is thermal conductivity of the stainless steel pot and minus sign indicated shows that it obeys second law of thermodynamics, $A$ is cross sectional area of $2 \mathrm{~mm}$ thickness steel through which heat flow to the oil, $\partial T / \partial x$ is temperature gradient in the direction of heat flow.

Thus, heat conducted through the pot is transmitted to the oil by convection within the hot oil and conducted to the interior of the food. Part of it also escapes to the atmosphere by radiation since the process is in an open system. The relationship between the three medium of heat transfer is expressed in equation 2 and 4.

$Q_{\text {cond }}=\left(Q_{\text {conv }}+Q_{\text {cond }}\right)+Q_{\text {rad }}$

$-K A_{\partial x}^{\partial T}=\left[h A\left(t_{s}-t_{f}\right)+\left(-K_{F} A \frac{\partial T}{\partial x}\right)\right]+Q_{r a d}$ 4

Given that convective heat transfer coefficient, $h$ of fat at $160^{\circ} \mathrm{C}$ is $580 \mathrm{~W} / \mathrm{m}^{2}{ }^{\circ} \mathrm{C}$ (Seruga and Budzaki, 2005), thermal conductivity of fat, $K_{F}$ is $27 \mathrm{~W} / \mathrm{m}{ }^{\circ} \mathrm{C}$, thermal conductivity of carbon steel, $K$ is $45 \mathrm{~W} / \mathrm{m}{ }^{\circ} \mathrm{C}$, (Holman, 1999). The fat is assumed to be at average room temperature, $t_{f}$ of $32{ }^{\circ} \mathrm{C}$ before heating. During experimentation, surface temperature of the pot, $t_{s}$ is taken to be $160{ }^{\circ} \mathrm{C}$ and the pot is assumed to be maintained at a level two-third filled with fat. Applying the above conditions, the rate of heat transfer by conduction, convection and radiation during frying are found to be as given below.

$$
\begin{aligned}
& 1428=1392+Q_{\text {rad }} \\
& Q_{\text {rad }}=36 \mathrm{~W}
\end{aligned}
$$

\section{Concept of moisture migration and fat uptake}

Moisture content plays a significant role in pore formation (Hussain et al., 2002). Fat absorption is dependent on the initial moisture content of the food product being fried. Foods are hygroscopic materials and carry significant quantities of bound water in their porous matrix. As a result, as water diffuses from the matrix during frying, pathways usually referred to as 'capillary pores' are created. The formation of capillary pores enhances oil absorption. Thermal processing of food causes physicochemical reactions that affect food structure. As food fries, the food moisture is converted to steam and releases under pressure. The type of process and the intensity of heating, coupled with the initial moisture content of the food product influence the final pore structure (Hussain et al., 2002). Many researchers have reported that the relationship between moisture loss and fat absorption is proportional and linear (Kassama and Ngadi, 2001); (Krokida et al., 2000).

The diffusion rate of the moisture into the fat and that of the fat through the capillary pores depend on temperature gradient across the heating medium. Since the two are proportional to one another, the basic equation giving the mass flux is expressed as (Ibarz and Barbosa-Canovas, 2003): 


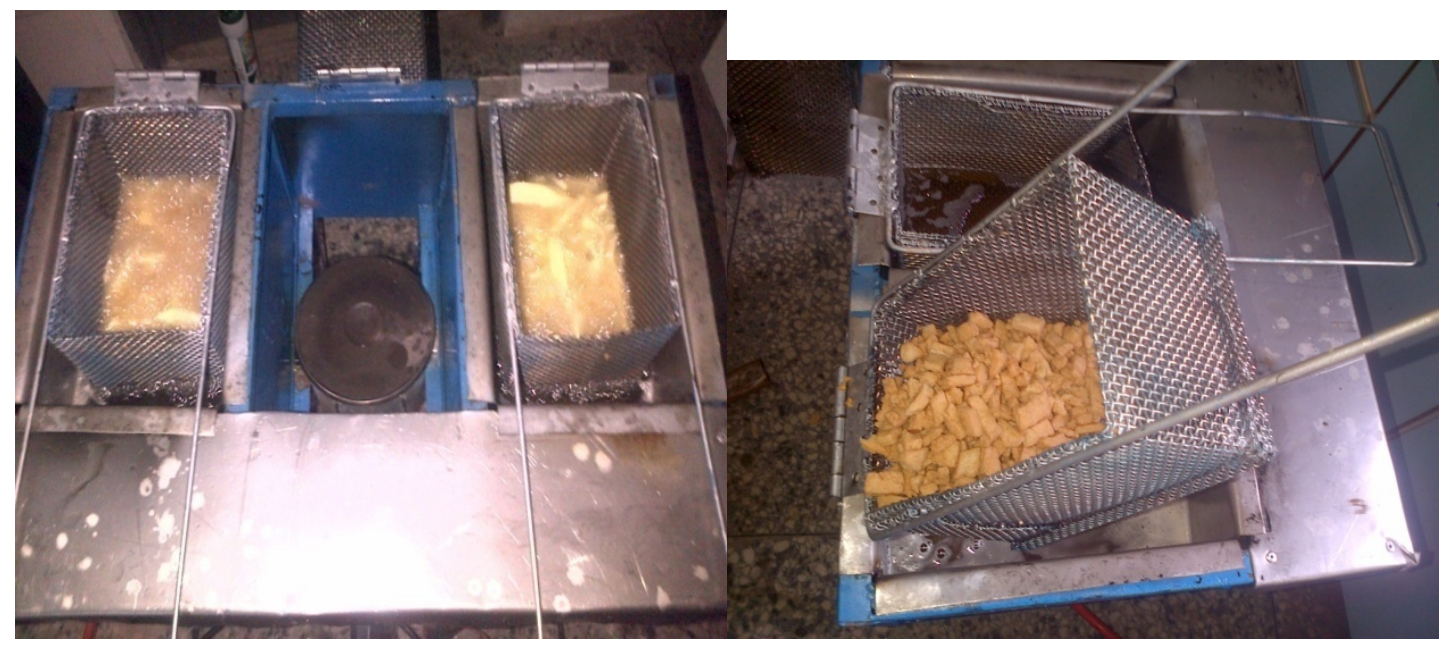

Figure 6.A (gradual changes during frying operation, B (chin-chin production ready for packaging).

$-\left(\frac{D_{F}}{L}\right)\left(C-C_{i}\right)=-\left(\frac{D_{M}}{L}\right)\left(C-C_{i}\right)$

Where $D_{F}$ and $D_{M}$ are diffusivity of fat and moisture respectively, $L$ is the thickness of the respective liquid film through which diffusion takes place, and $C_{i}$ and $C$ are the concentrations at the interface and within the liquid respectively.

The mass flux through the liquid mass becomes:

$$
K_{F}\left(C_{i}-C\right)=K_{M}\left(C_{i}-C\right)
$$

Hence the diffusivity of fat $\left(D_{F}\right)$ and diffusivity of moisture $\left(D_{M}\right)$ are related as follows:

$$
K_{F}=\frac{D_{F}}{L}, K_{M}=\frac{D_{M}}{L}
$$

Where $K_{F}$ is the thermal conductivity of fat and $K_{M}$ is the thermal conductivity of moisture. Hence $D_{F}$ has been determined under various heat sources in this study as the fat uptake.

\section{Performance evaluation of the machine}

The performance of the multi-heat source deep fryer was tested using wheat flour which was made into dough fried with different oils to produce chin-chin, namely Groundnut, Soya and Corn oils. Each of these oils was tested with different heat energy sources in the multisource fryer i.e. Charcoal, Gas and Electricity.

\section{Procedure}

Materials used for the production of chin-chin are flour, sugar, eggs, baking powder, salt and margarine. $2 \mathrm{~kg}$ of wheat flour was weighed into a container, four pieces of egg, $200 \mathrm{~g}$ of flour, four tea spoon of baking powder, one table spoon of salt, $200 \mathrm{~g}$ of margarine and $150 \mathrm{ml}$ of water. Figure 5 shows flow chart for the production of chin-chin.

\section{Experimentation}

\section{Determination of fat uptake in the chin-chin}

Material used for this experimentation includes Petroleum ether, $2 \mathrm{~g}$ of chin-chin sample, soxhlet extractor, running tap. The cups were dried in the oven at a temperature of $105{ }^{\circ} \mathrm{C}$ for one hour, it was cooled inside the desiccators and weighed. $2 \mathrm{~g}$ of the grounded samples was wrapped using tissue paper, each of the samples was then put inside a thimble. The soxhlet extractor was switch on and allowed to reach the set temperature $\left(135{ }^{\circ} \mathrm{C}\right.$ ) (Greg et al., 2008). The thimble was placed in a soxhlet extraction chamber and $80 \mathrm{ml}$ of petroleum ether was measured in the weighed cup. The cups containing the petroleum either were put in the soxhlet extractor using the cup rack. The running tap was opened to allow for easy extraction. The soxhlet extractor was then set to boil for about 30 minutes and the solvent evaporated for another 30 minutes and moves up into the condenser stage for about 10 minutes where it was converted into liquid that trickles into the extraction chamber containing the 


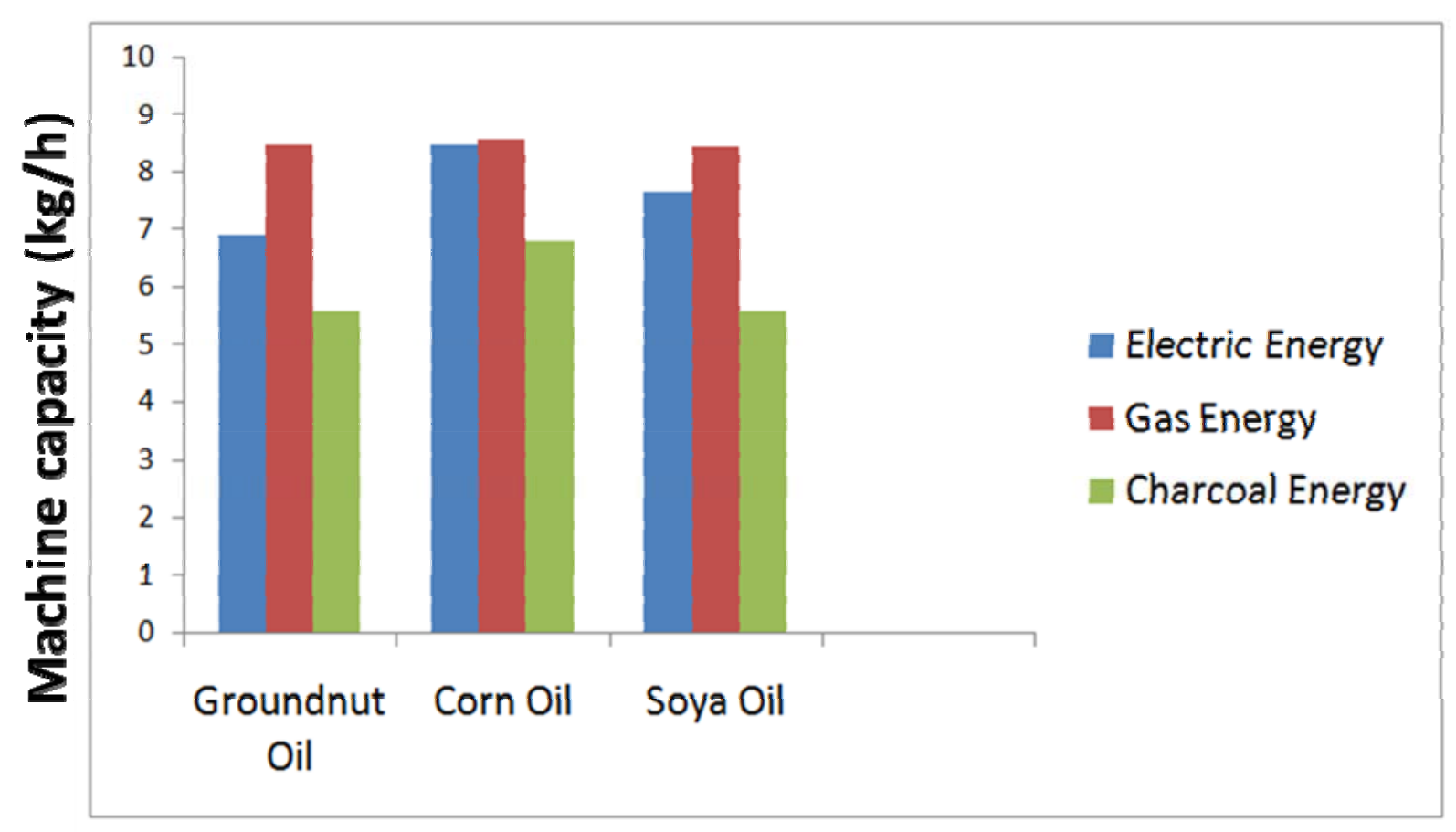

Figure 7.Machine capacity $(\mathrm{kg} / \mathrm{h})$ using different oils and different heat sources.

sample. At the end of the extraction process, it finally goes into the rinsing stage for about 5 minutes and the cup containing the lipid was removed (Greg et al., 2008). The cups were dried in the oven for about 10 minutes at a temperature of $60{ }^{\circ} \mathrm{C}$. The cups were weighed and the readings were recorded.

\section{Determination of vitamin A in the production of chin- chin}

The chin-chin fried from different oil sources and from different heat sources was grounded separately in to small pieces using mortar and pestle. $5 \mathrm{~g}$ of each grounded sample was dissolved in $50 \mathrm{ml}$ of distilled water and then left for one hour. $0.5 \mathrm{ml}$ of each of the dissolved solution containing the samples was injected into the Val using needle and syringe. They were left for five minutes to settle and were put inside the I-check, Bio Analyt, quantitative equipment for vitamin A determination. The readings were taken appropriately.

\section{RESULTS AND DISCUSSION}

Deep-fat frying is a complex process that involves simultaneous heat and mass transfer. The process induces a variety of physicochemical changes in both the dough and the frying medium. The mechanisms of water evaporation and oil absorption are intimately related. When the dough is immersed in hot oil, the initial fat absorption takes place through surface wetting, depending on the surface structure and by capillary action. As the product heats up, moisture is converted to steam, migrates to the surface and eventually into the frying medium due to a pressure differential. The vapour being release from the dough surface impedes fat intrusion into the product during surface boiling. Thus, the colour of the dough gradually changes to brown as shown in Figure 6A. Heat conducted by the frying pot during production of chin-chin as shown in Figure 6B is transferred by combination of convection within the hot oil, conduction to the interior of the food and radiation heat losses.

The capacity of the machine as shown in Figure 7 using Groundnut, Corn and Soya oils (GCS) was found to be $6.90,8.50$ and $7.68 \mathrm{~kg} / \mathrm{h}$ respectively for electric energy source; $8.50,8.60$ and $8.46 \mathrm{~kg} / \mathrm{h}$ respectively for gas energy source; and $5.60,6.80$ and $5.60 \mathrm{~kg} / \mathrm{h}$ respectively for charcoal energy source. From the experimental results, conductive heat transfer or heat requirement of the machine was found to be $1428 \mathrm{~W}$, with heat required for effective frying as $1392 \mathrm{~W}$ and heat losses by radiation as $36 \mathrm{~W}$.

The fat uptake of the chin-chin fried with GCS using electric, gas and charcoal energy sources shows appreciable result. The fat uptake of the chin-chin fried with GCS oils using electricity as heat source was found to be $0.49,0.41$ and 0.43 respectively as shown in Table 1. Thus the chin-chin fried with corn oil gave the least fat uptake followed by the soya oil when using electricity. The fat uptake of the chin-chin fried with GCS oils using gas as heat source was $0.51,0.46$, and 0.47 respectively as shown in Table 2. Thus the chin-chin fried with corn oil 
Table 1. Fat uptake of chin-chin after frying using electricity.

\begin{tabular}{llll}
\hline Oil & Groundnut & Corn & Soya \\
\hline weight of cup $(\mathrm{g})$ & 44.95 & 44.95 & 43.56 \\
weight of samples $(\mathrm{g})$ & 2 & 2 & 2 \\
weight after extraction $(\mathrm{g})$ & 45.44 & 45.36 & 43.99 \\
weight of oil $(\mathrm{g})$ & 0.49 & 0.41 & 0.43 \\
\hline
\end{tabular}

Table 2. Fat uptake of chin-chin after frying using gas.

\begin{tabular}{llll}
\hline Oil & Groundnut & Corn & Soya \\
weight of cup $(\mathrm{g})$ & 44.43 & 44.71 & 44.83 \\
weight of samples $(\mathrm{g})$ & 2 & 2 & 2 \\
weight after extraction $(\mathrm{g})$ & 44.94 & 45.17 & 45.30 \\
weight of oil $(\mathrm{g})$ & 0.51 & 0.46 & 0.47 \\
\hline
\end{tabular}

Table 3. Fat uptake of chin-chin after frying using charcoal

\begin{tabular}{llll}
\hline Oil & Groundnut & Corn & Soya \\
weight of cup $(\mathrm{g})$ & 44.82 & 44.96 & 44.83 \\
weight of samples $(\mathrm{g})$ & 2 & 2 & 2 \\
weight after extraction $(\mathrm{g})$ & 45.49 & 45.53 & 45.46 \\
weight of oil $(\mathrm{g})$ & 0.67 & 0.57 & 0.63 \\
\hline
\end{tabular}

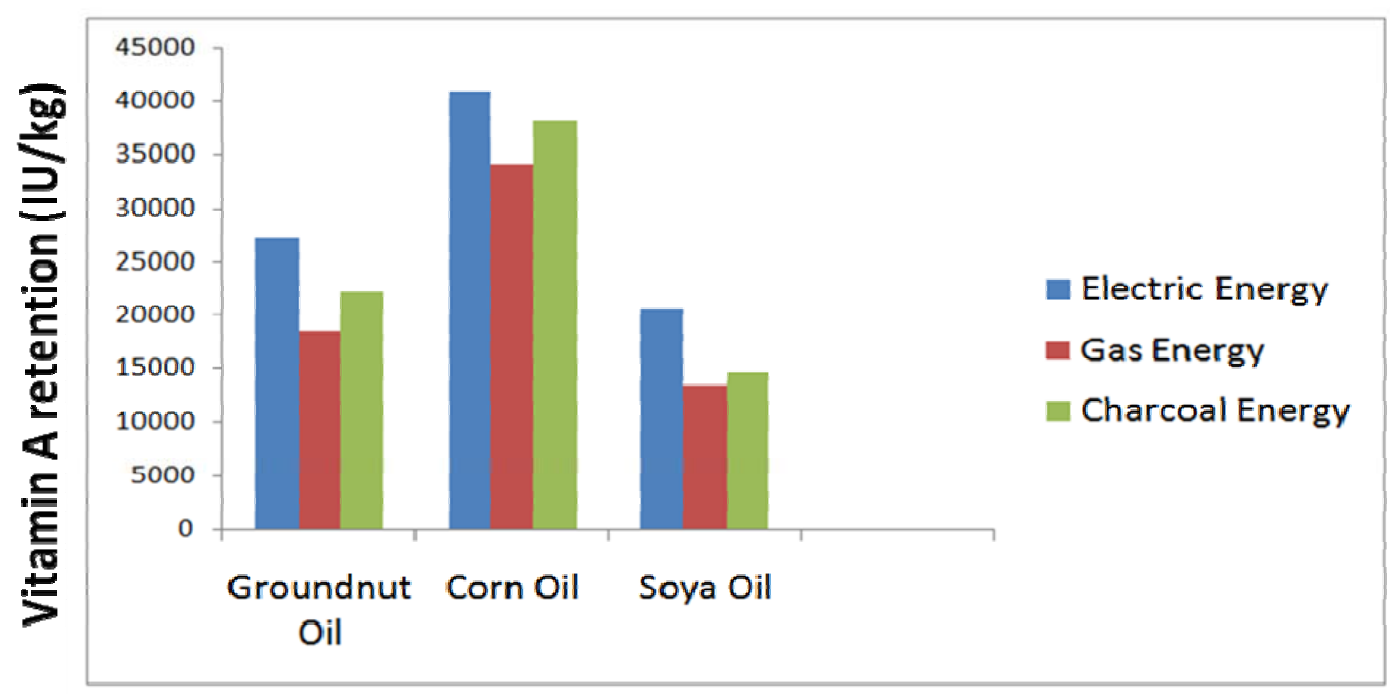

Figure 8. Vitamin A retention in chin-chin during frying using different heat sources.

gave the least fat uptake followed by the soya oil when using gas. The fat uptake of the chin-chin fried with GCS oils using charcoal as heat source was $0.67,0.57$ and 0.63 respectively as shown in Table 3 . Thus the chin-chin fried with corn oil gave the least fat uptake followed by the soya oil when using charcoal. The fat uptake of the chi-chi fried with groundnut oil was found to be on the high side in all the heat sources which may likely be due to the presence of unsaturated double bonds.

Figure 8 illustrates the relationship between the effects of degradation of vitamin A in chin-chin production using different heat sources. This is used to estimate which heat source and under what oil gives a low retention of Vitamin $\mathrm{A}$. The trend of degradation of 
vitamin $A$ level shows that gas and charcoal energy sources degrades vitamin A level faster with vitamin A retention $13515 \mathrm{IU} / \mathrm{kg}$ and $14727 \mathrm{IU} / \mathrm{kg}$ respectively using soya oil as frying medium. When using groundnut oil as frying medium, gas and charcoal also degrades vitamin $\mathrm{A}$ faster with vitamin A retention $18485 \mathrm{IU} / \mathrm{kg}$ and 22242 $\mathrm{IU} / \mathrm{kg}$ respectively. When using corn oil as frying medium, gas and charcoal equally degrades vitamin A faster with vitamin A retention $34242 \mathrm{IU} / \mathrm{kg}$ and $38182 \mathrm{IU} / \mathrm{kg}$ respectively. Gas and charcoal degrades vitamin A faster with low retention in all frying medium. This is likely to be as a result of incomplete combustion in both the gas and charcoal. The gas produced yellow flame instead of the blue flame because the space constructed for the oxygen inflow was too wide. The charcoal produced smoke when lighted up. These contain carbon monoxide which is poisonous to the health. However, vitamin A degradation using electric energy is slow with high vitamin A retention $20606 \mathrm{lU} / \mathrm{kg}, 27273 \mathrm{IU} / \mathrm{kg}$ and $41030 \mathrm{IU} / \mathrm{kg}$ in soya, groundnut and corn oil respectively.

\section{CONCLUSION}

In the production of chin-chin, conductive heat transfer is equal to the combination of convective heat transfer within the hot oil, conductive heat transfer to the interior of the food and heat losses as a result of radiation. Chinchin fried with corn oil gave the least fat uptake followed by soya oil. However, these are recommendable in accordance to the conviction that high fat intake in human system causes cardiovascular diseases (Hoffman et al., 2006). Electric energy has high vitamin A retention in all frying medium and the machine capacity ranges from $5.60-8.60 \mathrm{kgh}^{-1}$ depending on heat source.

\section{REFERENCES}

Ballard T, Mallikarjunan $\mathrm{P}(2006)$. The effect of edible coatings and pressure frying using nitrogen gas on the quality of breaded fried chicken nuggets. Journal of Food Science 71(3): 259-264.

Dogan SF, Sahin AC, Sumnu G(2005). Effects of soy and rice flour addition on batter rheology and quality of deep-fat fried chicken nuggets. Journal of Food Engineering 71(1): 127-132.
Garayo J, Moreira R(2002). Vacuum frying of potato chips. Journal of Food Engineering 55, 181-191.

Greg S, David C, Zabrowski D(2008). Vulcan electric fryer performance test: Application of ASTM standard method F 1361- 07. Food Science and Technology Center 50111.08.04.

Hoffman LC, Botha SS, Britz TJ(2006). Sensory properties of hotdeboned ostrich (Struthio camelus var. domesticus) Muscularis gastrocnemius, pars interna. Meat Science and preservation 72(4): 734-740.

Holman JP(1999). Heat transfer. $8^{\text {th }}$ edition, New York: McGraw Hill, Inc.

Hussain MA, Rahman MS, Ng CW(2002). Prediction of pore formation (porosity) in foods during drying: generic models by the use of hybrid neural network. Journal of Food Engineering 51: 239-248.

Ibarz A, Barbosa-Canovas GV (2003). Unit Operation in Food Engineering. New York: CRC Press.

Innawong B, Mallikarjunan P, Marcy J, Cundiff J(2006). Pressure conditions and quality of chicken nuggets fried under gaseous nitrogen atmosphere. Journal of Food Processing and Preservation 30: 231-245.

Jimoh $M O(2014)$. Modeling and evaluation of palm nut drying rate during mechanical cracking. The Pacific Journal of Science and Technology 15(2): 36-42.

Kassama LS, Ngadi MO(2001). Development of pores and pore size distribution in chicken meat during deep-fat frying. Canadian Society of Agricultural Engineering, Mansonville, QC, Paper No. 01-322.

Krokida MK, Oreopoulou V, Maroulis ZB(2000). Water loss and oil uptake as a function of frying time. Journal of Food Engineering 44: 39-46.

Mellema $M(2003)$. Mechanism and reduction of fat uptake in deep-fat fried foods. Trends in Food Science \& Technology 14: 364-373.

Pinthus EJ, Weinberg P, Saguy IS(1995). Oil uptake in deep fat frying as affected by porosity. Journal of Food Science 60(4): 767-769.

Seruga B, Budzaki S(2005). Determination of thermal conductivity and convective heat transfer coefficient during deep fat frying of krostula dough. Europe Food Research Technology 221: 351-356.

Shyu S-L, Hau L-B, Hwang LS(2005). Effects of processing conditions on the quality of vacuum-fried carrot chips. Journal of Science, Food and Agric. 85: 1903-1908.

Teye GA, Sheard PR, Whittington FM, Nute SA, Wood JD(2006). Influence of dietary oils and protein level on pork quality, effects on muscle fatty acid composition, carcass, meat and eating quality. Meat Science 73(1): 157-165

Yamsaengsung R, Moreira RG(2002). Modeling the transport phenomena and structural changes during deep-fat frying, Part 1, Model development. Journal of Food Engineering 53: 1-10. 